\title{
A Study on the Classification and Resource Utilization of Solid Waste in China
}

\author{
Du Xiangwan ${ }^{1}$, Qian Yi' ${ }^{2}$, Chen Yong ${ }^{3}$, Ling Jiang ${ }^{4}$, Liu Xiaolong ${ }^{5}$, Yang Bo ${ }^{5}$, Jiang Lingling ${ }^{5}$, Ge Qin ${ }^{5}$, Huhetaoli ${ }^{3}$, \\ Liu $\mathrm{Xi}^{4}$, Sun Xiaofei ${ }^{2}$ \\ 1. China Academy of Engineering Physics, Mianyang 621900, Sichuan, China \\ 2. School of Environment, Tsinghua University, Beijing 100084, China \\ 3. Guangzhou Institute of Energy Conversion, Chinese Academy of Sciences, Guangzhou 510640, China \\ 4. Solid Waste and Chemicals Management Center, Ministry of Environmental Protection of the People's Republic of China, Beijing \\ 100029, China \\ 5. CAE Center for Strategic Studies, Beijing 100088, China
}

\begin{abstract}
China is a populous country and the largest producer of solid waste in the world. With limited per capita resources and significantly lower environmental capacity than the world average, China should cherish its resources and protect its environment even more fiercely. Solid waste is one such useful resource and can be a source of wealth. The amount of China's solid waste is continually increasing, due to improper handling, causing problems such as environmental pollution and social instability. Therefore, attention should be paid to ecological civilization construction in China. This paper analyzes the current situation of solid waste resource utilization in China and the potential for its improvement, concluding that China has the means and the know-how to classify and utilize the solid waste resources and the benefits of such classification and utilization will be significant. Further, strategic directions, strategic objectives, a development path, and policy suggestions for solid waste resource utilization in China are suggested.
\end{abstract}

Keywords: Solid waste; classification; resource utilization; strategic objective; policy suggestion

\section{Introduction}

Solid waste is mainly produced in industries, households, construction sites, agricultural fields, etc. With the world's largest population and the largest economy among developing countries, China's consumption of natural resources and the resulting waste production are highest in the world. The current accumulation of various types of solid wastes in China is approximately $8 \times 10^{10} \mathrm{t}$. Improvement in people's living standards and rapid urbanization is leading to increasing solid waste production every year. The annual output has increased to more than $1 \times 10^{10} \mathrm{t}[1]$. The disposal and utilization of greenhouse gases emitted in various production processes and the environmental impact of cross-regional toxic and hazardous substances has become a major global problem and has resulted in great environmental pressure on China. The improper handling of such large amounts of generated and accumulated waste has lead, and continues to lead, to resource wastage, affecting social stability and leading to other issues. However, waste is not entirely useless. Under certain technological and economic conditions, several types of waste can be converted into useful resources and energy, becoming a valuable asset. It is similar to "secondary mining" with huge potential. If solid waste can be classified, recycled, and reduced at the source, the use of primary natural resources

Received date: June 16, 2017; Revised date: July 12, 2017

Corresponding author: Du Xiangwan, China Academy of Engineering Physics, Academician; Chinese Academy of Engineering, Academician. Major research fields include applied physics, strong laser technology and energy strategy research. E-mail: duxw@cae.cn

Funding program: CAE Advisory Project “Several Strategic Issues on Eco-Civilization Construction (Phase II)” (2015-ZD-16)

Chinese version: Strategic Study of CAE 2017, 19 (4): 027-032

Cited item: Du Xiangwan et al. A Study on the Classification and Resource Utilization of Solid Waste in China. Strategic Study of CAE, https://doi.org/10.15302/ J-SSCAE-2017.04.005 
in industrial production, construction, household work, agricultural production, etc. can be significantly decreased. Improving resource utilization could lead to significant environmental, economic, and social benefits. Based on the classification and the source of solid waste in China, three categories of solid waste were considered in this study: "urban mining", rural waste, and industrial solid waste.

\section{Analysis of the present status and benefits of China's solid waste classification and recycling system}

\subsection{Present Status of China's solid waste classification and recycling}

China has established a strategic approach to comprehensive recycling, by formulating a framework for recycling. In recent years, China has conducted pilot demonstrations of solid waste recycling in various areas, effectively promoting solid waste classification, and the recycling industry and technology. In 2015, China's solid waste production was approximately $1.16 \times 10^{10} \mathrm{t}$, of which, $3 \times 10^{9} \mathrm{t}$ was from urban mining (mainly construction waste, garbage, and renewable resources), $5.3 \times 10^{9} \mathrm{t}$ from rural waste (mainly livestock and poultry manure and agricultural waste), and $3.3 \times 10^{9} \mathrm{t}$ from industrial waste (tailings accounted for the most) (Fig. 1) [2]. At present, with regard to urban mining, i.e. the recovery of renewable resources in China for basic purposes, domestic waste incineration accounts for approximately $35 \%$ of the clearance amount, while the contribution of construction waste recycling is low. With regard to rural waste in the form of rural municipal waste, the recycling rate of agriculture and forestry waste is approximately $80 \%$, while the recycling rate of aquaculture waste is approximately $40 \%$ [3]. The recycling rate of industrial solid waste is approximately $60 \%$.

\subsection{Analysis of the solid waste classification and recycling efficiencies in China}

The recycling of solid waste can not only solve environmental problems such as the destruction of ecological environment caused by improper solid waste disposal, it can also reduce the exploitation of native resources, alleviate the shortage of resources in China, conserve the land resource, stimulate investment, increase tax revenue, and increase employment and farmers' income, while leading to social stability, and significant environmental, social, and economic benefits. With the development of the economy and the society, the production of various types of solid waste in China will increase each year. Forecast analysis shows that the development potential of solid waste recycling is significant. The benefit analysis conducted in this study is shown in Table 1. The output of urban mining is predicted to reach $8 \times 10^{9} \mathrm{t}$ in 2030 . The recovery value of the main component of urban mining is expected to reach 2.14 trillion $\mathrm{RMB}$, while the amount of rural waste should reach $5.6 \times 10^{9} \mathrm{t}$

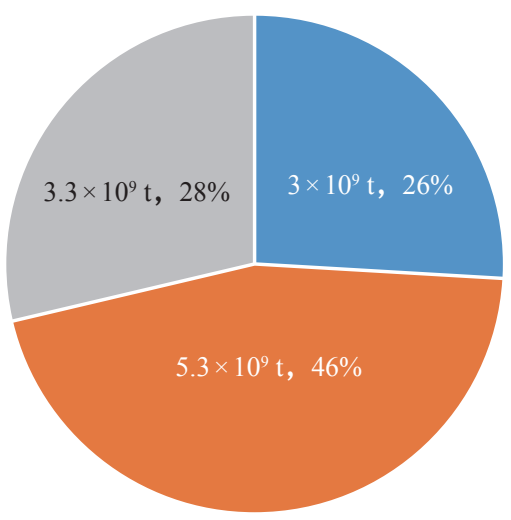

Rural waste; Industrial solid waste; U Urban mining

Fig. 1. China's solid waste production in 2015.

Table 1. Analysis of utilization benefits of solid wastes in China.

\begin{tabular}{|c|c|c|c|}
\hline Waste category & Name & 2020 & 2030 \\
\hline \multirow[t]{4}{*}{ Urban mining } & Production $\left(\times 10^{8} \mathrm{t}\right)$ & 50 & 80 \\
\hline & Main renewable resource recovery value (trillion $\mathrm{RMB}$ ) & 0.93 & 2.14 \\
\hline & Reduction of $\mathrm{SO}_{2}\left(\times 10^{4} \mathrm{t}\right)$ & 120 & 260 \\
\hline & Employment potential $\left(\times 10^{4}\right.$ people $)$ & 2000 & 3000 \\
\hline \multirow[t]{6}{*}{ Rural waste } & Production $\left(\times 10^{8} \mathrm{t}\right)$ & 54 & 56 \\
\hline & Total utilization of resources $\left(\times 10^{8} \mathrm{t}\right.$ of standard coal $)$ & 8.43 & 9.93 \\
\hline & Investment benefits (trillion RMB) & 3.37 & 3.97 \\
\hline & Emission reduction, $\mathrm{CO}_{2}\left(\times 10^{8} \mathrm{t}\right)$ & 22.51 & 26.51 \\
\hline & Emission reduction, $\mathrm{SO}_{2}\left(\times 10^{8} \mathrm{t}\right)$ & 170 & 200 \\
\hline & Employment potential $\left(\times 10^{4}\right.$ people $)$ & 1475 & 1142 \\
\hline \multirow[t]{4}{*}{ Industrial solid waste } & Production $\left(\times 10^{8} \mathrm{t}\right)$ & 35 & 30 \\
\hline & Comprehensive utilization ratio (\%) & 70 & 80 \\
\hline & Investment benefits (trillion RMB) & 1.08 & 1.35 \\
\hline & Employment potential $\left(\times 10^{4}\right.$ people $)$ & 200 & 150 \\
\hline
\end{tabular}


The resource use can be equal to $1 \times 10^{9} \mathrm{t}$ of standard coal, producing an investment benefit of 3.97 trillion RMB. Meanwhile, the industrial solid waste production should reach $3 \times 10^{9} \mathrm{t}$, with economic benefits from key industrial solid waste resources being up to 1.35 trillion RMB. China's solid waste classification and recycling will reach globally advanced levels, potentially creating approximately 40 million jobs. Thus, it can become an important supporting factor for China's strategic emerging industries.

\subsection{Outstanding problems of China's solid waste classification and recycling}

In recent years, China's solid waste recycling systems have achieved some success. However, many outstanding problems remain. First, China's solid waste classification and recycling systems are imperfect. They are non-standardized systems with low recycling efficiencies, among several other defects [4]. Second, solid waste classification and recycling systems lack high-level designs, according to a complete life cycle assessment. Based on the traditional development model of China, the state has divided the management functions of production, life, and recycling in the design of the system, and has failed to consider the objective laws of material flows. In the implementation of the system, the Ministry of Industry and Information Technology, the National Development and Reform Commission, the Ministry of Environmental Protection, and other departments, have separate responsibilities. However, the management boundaries are ambiguous and there is a lack of macro-level strategic guidance. Market development suffers from a lack of government funds, a lack of market incentives, and punitive fiscal and taxation systems, while industries lack autonomous power. Third, there is a lack of awareness about recycling, due to low social participation in recycling of wastes. For a long time, government and enterprise information disclosure has not been sufficient for the classification of solid waste collection, utilization, and disposal. Moreover, government lacks the ability to prevent and control secondary pollution due to the disposal process. The lack of public understanding of solid waste recycling has led to the "proximity effect". Finally, China's solid waste recycling system still lacks the technological support for sustainable industrial development. China does not possess any major integrated technology and product systems required for emission reduction efficiency enhancement and cross-industry synergistic utilization of solid waste. China's overall resource utilization is approximately 10-15 years behind advanced international levels [5].

China needs to resolve the aforementioned challenges and problems as soon as possible to improve the classification and utilization of solid wastes and ensure the vigorous development of their industries. In the process of building a beautiful China and realizing a great rejuvenation of the Chinese dream, China will gradually shift its economy towards sustainable and green developments.

\section{Strategic principles, objectives, and road map of China's solid waste classification and recycling}

\subsection{Strategic principles}

To realize green transformation and ecological civilization construction, China needs to consider solid waste classification and recycling as an important part of the national resource and environmental management strategy. With guidance from the "Government leads, industry supports; source reduction, disposal restriction; elaborate classification, and complete circulation" campaign, solid waste classification and recycling will gradually become an important strategy for emerging industries, which will support China's sustainable development.

Government leads, industry supports. The coordination between government macro-guidance and market allocation of resources is required for rational allocation of resources to relevant parties based on their rights and interests, to form multi-benefit sharing, win-win long-term mechanisms, and to nurture the autonomous power of industries. Industrial development must also be led with scientific and technological innovation, while vigorously promoting the high value-added clean production of technology with independent intellectual property rights, valuable resource extraction, and large-scale utilization, in order to protect the effective supply of secondary resources and production capacity.

Source reduction, disposal restriction. A coordination of China's economic and social developmental strategies is required to reduce social resource consumption and waste generation intensity. A goal should be set to weaken the environmental impact of production processes and the entire life cycle of the product, while improving the efficiency of resource recycling, gradually reducing the mining of metal mineral resources, imposing restrictions on non-metallic mineral resource mining activities, promoting industrial eco-design, product eco-design, and green supply chain construction, vigorously developing clean production, circular economy, eco-industrial park, and promoting the traditional industrial chain of green transformation, in order to reduce the amount of solid waste from the source, improve the utilization of resources, and expand the scale of green product supply. The disposal of solid waste through landfills, incineration, etc., should be limited, forcing solid waste to be used as resources and in energy production.

Elaborate classification, complete circulation. This is required to coordinate China's resource supply capacity and strategic needs, while classifying and managing solid waste via resource endowment, from "safe final disposal" to "recycling", giving priority to the extraction of iron, ten non-ferrous metals, and other strategic resources that can support economic devel- 
opment, to manage strategic reserves of solid waste containing important strategic resources (such as rare metals and rare earth elements), to improve the recycling capacity of renewable resources, and classify them into non-metallic mineral resources and energy (such as electricity, heat, and biogas) and fertilizer resources. Active participation in international resource recycling is also required for full use of the imported international quality mineral resources and renewable resources.

\subsection{Strategic objectives}

By 2020 (strategy implementation period): The scale of solid waste recycling will be significantly expanded, with the development of resource recycling having resulted in considerable benefits. The adverse effects and potential risks of solid waste on environmental quality and human settlements will have been effectively controlled.

By 2025 (critical transition period): China's recycling industry will have continued to expand the overall scale of indus- trial development to reach the high-end international level. The initial formation of a resource efficient cycle of development model will lead to economic and social development and resource energy consumption becoming relatively decoupled.

By 2030 (sustainable development period): Economic and social development, consumption of resources and energy, and solid waste production will have achieved decoupling, while China's solid waste classification and recycling system will have reached an advanced international level, with an output value of 7-8 trillion RMB, creating 40000-50000 jobs, and becoming an important pillar industry of China's strategic emerging industries (Fig. 2).

\subsection{Road map}

3.3.1 Building a green consumption model, and promoting the development of city mining

By 2020, the scale of renewable resource recovery will be expanded, and a multi-channel classification and recycling sys-

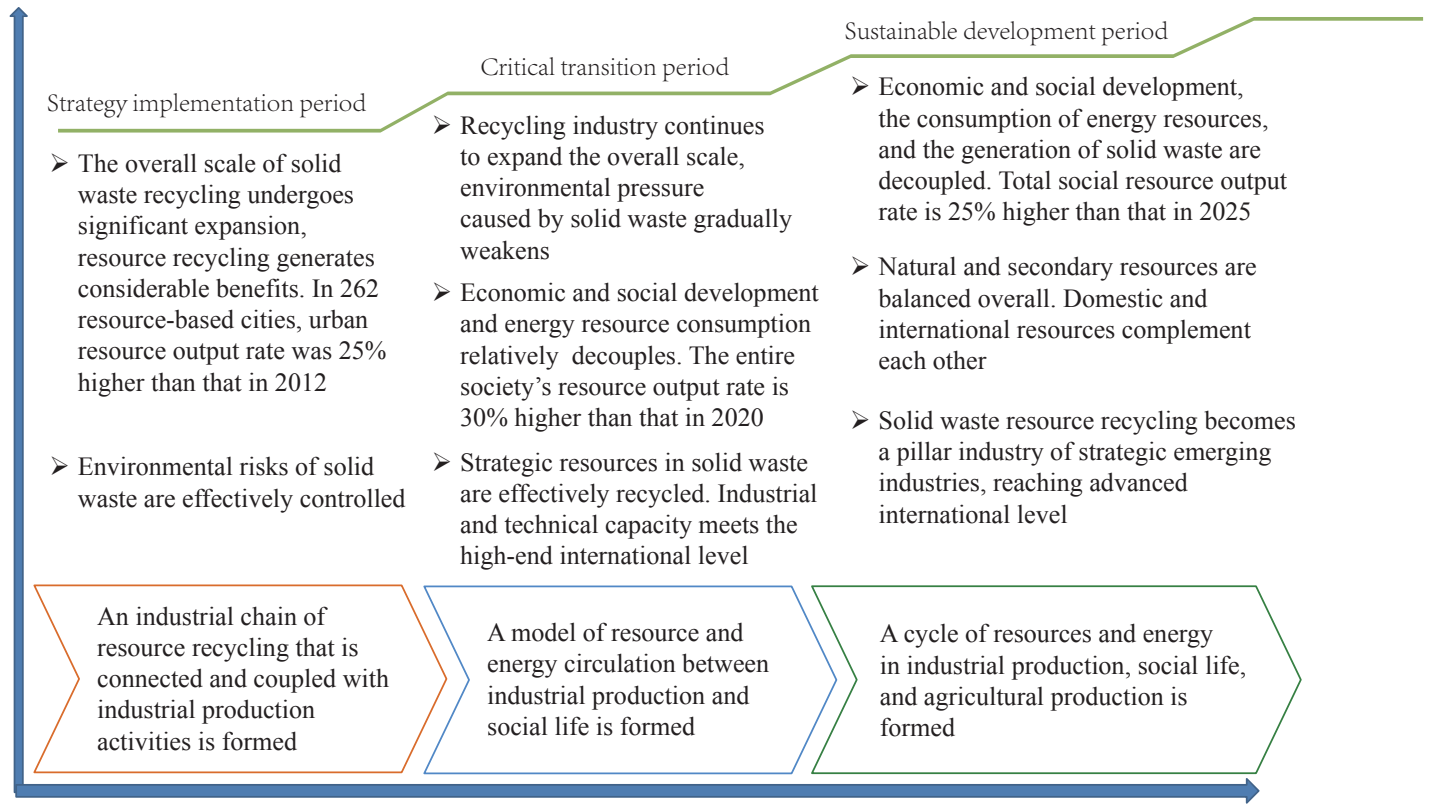

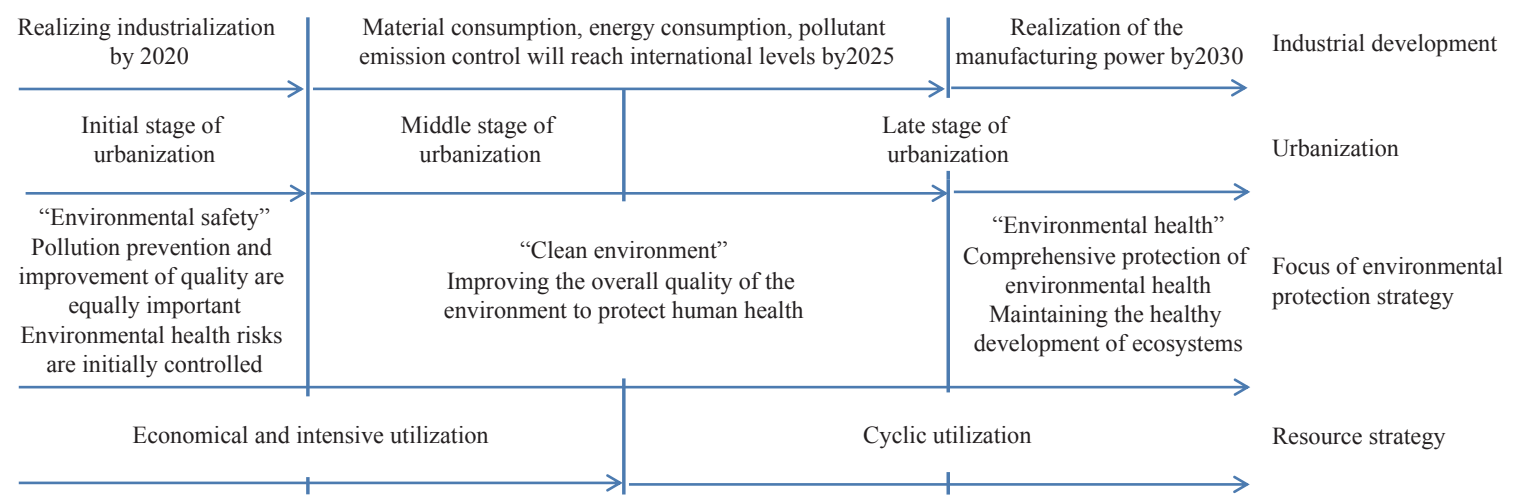

Fig. 2. Strategic objectives of China's solid waste utilization. 
tem will be built. Renewable resource recovery and garbage removal treatment systems should be promoted in urban areas as a "dual integration network". In prefecture-level cities, the rate of coverage of classification and collection of municipal wastes will be above $25 \%$, while the recycling rate will be above $35 \%$. By 2025, the capacity for classification collection efficiency and recycling of municipal waste and renewable resources will be improved. In prefecture-level cities, the rate of coverage classification and collection of municipal solid wastes will be above $65 \%$, while the recycling rate will be above $45 \%$. By 2030 , a strategy involving the green building materials industry will include promoting the recycling of construction waste resources, with construction waste becoming the main raw material for the building materials industry. In prefecture-level cities, the coverage rate of classification and collection of municipal waste will be above $90 \%$, while the recycling rate will be above $60 \%$.

3.3.2 Promoting eco-agricultural production mode and rural waste utilization

The modes of agricultural production and living should be improved, the construction of ecological agriculture, as well as the collaborative recycling of agricultural waste (mainly energy and organic matter) and municipal waste at a nearby location should be promoted. Agricultural surplus polygeneration systems, forestry surplus resources and energy utilization systems, and livestock and poultry manure energy and chemical systems should be developed to enhance the utilization of rural waste resources. By 2020, the indiscriminate dumping of rural garbage, the burning of agricultural and forestry biomass wastes, and the voluntary discharge of livestock and poultry breeding wastewater will be eliminated. Agricultural production areas will realize the regional recycling of agricultural resources. By 2025 , rural living waste will largely be harmlessly managed. To realize a beautiful countryside by 2030 and set up a new pattern of sustainable agricultural development, i.e., the formation of the circulation of ecological agriculture that makes full use of the biomass resources, rural waste will undergo basic recycling at a nearby location.

3.3.3 Promoting green transformation of industrial development and improving resource utilization efficiency

By 2020, clean production levels should be achieved in key industries across the industrial chain, such as the iron and steel, nonferrous metals, and chemical, by reducing the production intensity and terminal disposal of solid waste. Environmental risk will be effectively controlled, while the total amount of recycling will be significantly expanded. By 2025 , with the enhancement of the industrial product eco-design and green supply chain design level, the elaborate classification of industrial solid waste will be significantly improved. Industrial solid waste generation and industrial value-added growth will be decoupled completely. By 2030, the microcirculation of industrial solid waste recycling among enterprises will be developed, with small cycles between sites, medium circulation among regions, and large cycles among societies. Secondary resources will become an important component of industrial production activities.

\section{Policy suggestions for China's solid waste classification and resource recycling}

\subsection{Enhancing strategic position, consolidating policy and institutional basis, improving technical standard systems, and building a healthy market environment}

Solid waste recycling needs to rise to the strategic level of national ecological civilization construction to enable the implementation of plans and the application of output rate, recycling rate, and other quantitative indicators. Moreover, China should be considered as an important strategic indicator of ecological civilization, and should be brought into the country's social development evaluation and government performance appraisal system. Solid waste classification and recycling laws and regulations should be improved and integrated into recycling systems to benefit the recycling industries. In view of the existing system's indifference to recycling strategies, the legal responsibility and management requirements, such as the control, recycling, and comprehensive utilization, should be clarified for solid waste related industries and the relevant sources and the development of the extension system of production and consumption should be promoted. A sound pollution control standard for the resource utilization process and a quality control standard for the comprehensive utilization of products should be established to promote the comprehensive utilization of products that successfully enter the consumer market. The establishment of a new type of social management system and a model to resolve solid waste recycling challenges will cause a proximity effect. A joint supervision and disciplinary mechanism should be established, and the resource industry market should be required to clean up and rectify.

\subsection{Strengthening the national top-level design and implementing integrated management strategies}

A national five-part developmental concept of innovation, coordination, green, opening, and sharing should be implemented, based on the entire life cycle assessment of solid wastes, combined with a national macro-strategy, including the overall plan of industrial solid waste classification and recycling, industrial structure adjustment, green manufacturing, and strategic emerging industry objective. Solid waste energy utilization should be combined with the national clean energy strategy. The emerging technologies for power generation from solid waste and biomass should be prioritized, and the utilization of alternative biomass and industrial solid waste energies should be promoted. The ecological red line should be combined with land space plan- 
ning, coordinating natural resources, and secondary resource development strategies. The development and utilization of secondary resource industry layouts should be coordinated, and the deep processing industry should be guided into the traditional resource gathering areas.

\subsection{Reform the development model, promote the full circulation of resources, and set the long-term goal of "country of no waste"}

The production mode should be reformed, the ecological industry chain that is reversing the flow of resources should be developed, and the resource-dependent development path should be changed. A reform of the mode of living should be guided, green consumer awareness should be established, the level of environmental awareness of the people should be enhanced, the solid waste classification and recycling should be included in the national education system, the awareness of the entire society on the urgency solid waste recycling should be improved, and an effective social supervision mechanism should be developed. A multi-level recycling model should be set for solid waste resources. The convergence cycle of solid waste in industrial production, agricultural production, urban, and rural life should be achieved gradually. The circulation system of solid waste classification and recycling for the entire society should be developed gradually, while striving to minimize the resource and energy consumption, maximize the utilization, and ultimately build a circular economic and social development model with China's characteristics, achieving the long-term goal of being the "country of no waste."

\subsection{Strengthening scientific and technological support, accelerating high-end industrial development}

A national science and technology plan (projects) should be established, the scientific and technological capacity-building for solid waste recycling should be strengthened, and the level of resource utilization should be improved. Focus should be on supporting research on common key technologies and key equipment for solid waste classification and recycling, as well as supporting equipment integration and independent innovation, such as efficient extraction of resources, process automation, and remanufacturing technology. The promotion and application of innovative technology should be accelerated while setting up major pilot demonstration projects and accelerating the industrialization process of solid waste classification and recycling. Relying on cloud computing, Internet + , Internet of Things, and other modern information technology systems will help build a comprehensive solid waste management and public information service system, which should be included in the intelligent city construction system to enhance the informatization level of solid waste environmental management.

\section{References}

[1] National Bureau of Statistics of the PRC. China statistical yearbook 2015 [M]. Beijing: National Bureau of Statistics of the PRC, 2015. Chinese.

[2] Chang Q F. Development and utilization of mineral resources and sustainable development [J]. China Mining, 2000, 9(6): 11-15. Chinese.

[3] China National Development and Reform Commission of the PRC. Annual report on comprehensive utilization of resources in China (2014) [EB/OL]. (2014-10-09) [2016-04-01]. http://www. ndrc.gov.cn/gzdt/201410/t20141009_628795.html. Chinese.

[4] Ju C H, Zhu L, Zhu H B, et al. Problems and countermeasures for the disposal of rural domestic wastes in China [J]. Safety and Environmental Engineering, 2015, 22(4): 99-103. Chinese.

[5] Li J H, Song Q B, Studying on the developing status, problems and suggestions of urban mining in China [J]. 2014, 36(12): 9699. Chinese. 